\title{
A mathematical model of soil moisture spatial distribution on the hill slopes of the Loess Plateau
}

FU Bojie (傅伯杰) ${ }^{1}$, YANG Zhijian (杨志坚) ${ }^{2}$, WANG Yanglin (王仰麟) ${ }^{3}$

\& ZHANG Pingwen (张平文) ${ }^{2}$

1. Department of Systems Ecology, Research Center for Eco-Environmental Sciences, Chinese Academy of Sciences, Beijing 100085, China;

2. Department of Mathematics, Peking University, Beijing 100871, China;

3. Department of Urban and Environmental Sciences, Peking University, Beijing 100871, China

Correspondence should be addressed to Fu Bojie (email: bfu@mail.rcees.ac.cn)

Received May 31, 2000

Abstract Based on important factors that affect soil moisture spatial distribution, such as the slope gradients, land use, vegetation cover, and surface water diffusion characteristics together with field measurements of soil moisture data obtained from the surface soil under different land use structures, a soil moisture spatial distribution model was established. The diffusion degree coefficient of surface water for different vegetations was estimated from soil moisture values obtained from field measurements. The model can be solved using the finite unit method. The soil moisture spatial distribution on the hill slopes in the Loess Plateau were simulated by the model. A comparison of the simulated values with measurement data shows that the model is a good fit.

Keywords: Loess Plateau, hill slope, soil moisture, mathematical model.

Soil moisture is not only an important component of soil, but also a critical determinant of its productivity. The transmission of all soil materials, including plant intake nutrients from soil, requires moisture ${ }^{[1]}$. Soil moisture is closely related to vegetation cover and land use ${ }^{[2]}$. The status of soil moisture influences the growth of plants and crops, and at the same time vegetation cover and land use can also influence the soil moisture content and its distribution ${ }^{[3,4]}$. Therefore, determining how to maintain soil moisture is very important for the semi-arid region of the Loess Plateau $^{[5-7]}$. Important progress in mathematic modeling of the vertical transmission of soil moisture from soil to plant and the absorption of soil moisture by plant roots has been made ${ }^{[8,9]}$ by the research of soil moisture on the Loess Plateau. Slope hydrology models focus mainly on rainfall-runoff and erosion-sediment ${ }^{[10,11]}$. However, the soil moisture spatial distribution prediction model is still a shortage in the loess hill slope. The content and distribution of soil moisture were obtained through the measurements or sampling in the field ${ }^{[12-14]}$. The objective of this paper is to develop a mathematical model for the spatial distribution of soil moisture on the loess hill slope by the analysis of important factors that influence soil moisture content and surface water diffusion characteristics. The model coefficient was estimated from soil moisture data measured at three hill slope transects. The spatial distribution of soil moisture on the hill slope was simulated 
using the model and then compared with measurement data from the field. This study is important for forecasting the spatial distribution of soil moisture on the hill slope of the Loess Plateau.

\section{Study area and methods}

The study area was the Yangjuangou catchment, which belongs to Yan'an city and covers an area of $2.02 \mathrm{~km}^{2}$. The regional topographic types are loess hills and gully landforms. The gully density is $2.74 \mathrm{~km} \cdot \mathrm{km}^{-2}$, which is typical for the loess hilly area. The region has a semi-arid continental climate with an average annual rainfall of $535 \mathrm{~mm}$. The rainfall is concentrated mainly between July and September and varies greatly from year to year. The soil in the study area is mainly derived from loess; it is fine silt to silt in texture and weakly resistant to heavy erosion. The erosion rate is severe with an average loss of $8979 \mathrm{t} \mathrm{km}^{-2} \mathrm{a}^{-1}$ between 1991 and 1996 ${ }^{[15]}$. The natural vegetation has been destroyed completely and the cultivation index is high. Land use types are mainly slope farmland, terrace farmland, orchard, grassland, and artificial woodland.

Three transects, with typical land use structures that have existed for about 15 years, were selected from the hill slopes of the study area. The land use structure combinations from foot to top of the hill were: grassland-slope farmland-woodland, slope farmland-grassland-woodland, and slope farmland-woodland-grassland. The grassland is natural grassland. The woodland is artificial locust woodland. The crops grown on the farmland are potatoes (Solanum tuberosum), beans (Phaseolus vulgaris) and millet (Panicum miliaceum). The slope gradients are nearly uniform ranging from $10^{\circ}$ to $30^{\circ}$ from the hill foot to the upper slope. The hill slopes have no irrigation. A portable TDR (Time Domain Reflectometry) instrument was used to measure soil moisture content on August 8 and 9, 1998. At least three different positions from top, middle and bottom were selected for each land use type. At each position, the slope gradient was recorded and three samples were taken to measure the moisture content at five depths: $0-10,10-20,20-30,30-$ 50 , and $70 \mathrm{~cm}$. There were 96 sample points altogether at the three transacts. After digging to different depths with a soil drill, the soil moisture content was measured by portable TDR.

\section{Conceptual model and mathematical model}

Rainfall, soil characteristics, slopes and land cover are important factors affecting soil moisture distribution $^{[16]}$. Since the soil characteristics of the loess area are uniform, the main factors that determine soil moisture are land cover, slope gradients, and the characteristics of surface water diffusion. We can construct a mathematical equation as follows:

$$
\frac{\partial}{\partial s}\left(k(s) \frac{\partial u}{\partial s}\right)+g \sin \theta=0,
$$

where $u$ is surface water flux rate; $g$ is gravitation acceleration; $s$ is a parameter of the length of an arc; $\theta$ is an included angle between a tangent line and a flat surface at each point, and is a function with $s$ as an argument; $k(s)$ is the diffusion degree of surface water for different vegetations, 
and a function of a constant within a finite area.

The physical meaning of the equation is that diffusion of surface water is in balance with gravitation along the slope. Soil moisture is determined by surface water and rainfall infiltrate into the soil on hill slopes. Under conditions of constant precipitation, the more the surface runoff, the less the soil moisture; and vice verse. There are two factors that affect surface runoff. One is the water flow rate: when the water flow is swifter, the water content that infiltrates the soil is less. Another is obstruction to water flow by vegetation. Under the condition of constant water flow rate, the greater the obstruction by vegetation to the water flow, the more the water that permeates into the soil. In the model, $u$ is surface water flow rate, $k$ is obstruction of vegetation to water flow. So, $k / u$ is an important value, which is a direct ratio to soil moisture. In eq. (1), $u$ is flow rate of surface water, $\frac{\partial u}{\partial s}$ is a convection of the flow in mechanics, $\frac{\partial}{\partial s}\left(\frac{\partial}{\partial s}\right)$ is a diffusion of the flow, $k(s)$ shows obstruction by vegetation to the diffusion, and the diffusion is balanced with gravitation along a tangent.

Using position and altitude at each sampling point, and using the insert value method to simulate real data, we could draw topographic curve of the hill slope (fig. 1) and take it as $h(x)$, where $x$ is the level coordinate of each point, $h(x)$ is the relative height from the lowest point to this point, and $h^{\prime}(x)$ is the slope gradient of this point. We could derive the altitude and slope gradient at each point.

From the definitions of $s$ and $\theta$, we know that $\frac{\partial}{\partial s}=\frac{1}{\sqrt{1+\left(h^{\prime}(x)\right)^{2}}} \frac{\partial}{\partial x}, \sin \theta=$

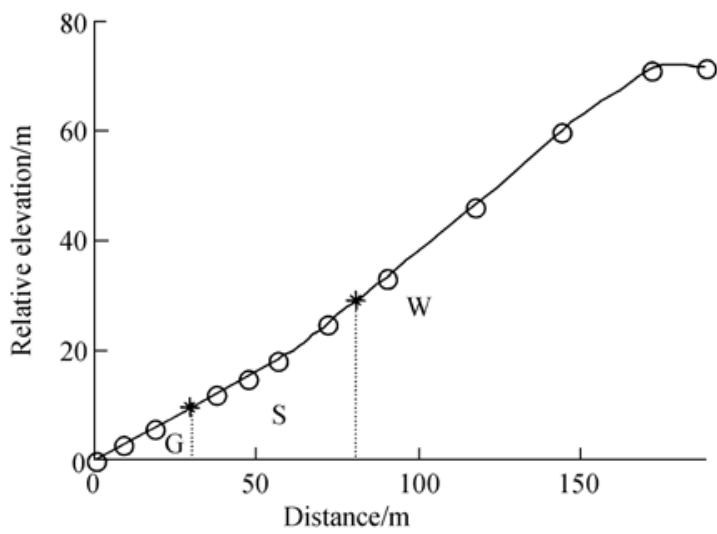

Fig. 1. The simulation of slope gradient and altitude for grassland-slope farmland-woodland slope. G, grassland; S, slope farmland; W, woodland. Real curve is topographic function $h(x)$, circles are sampling points of soil moisture; star points are boundary between different land uses.

$h^{\prime}(x) / \sqrt{1+\left(h^{\prime}(x)\right)^{2}}$. With this, we could deduce eq. (1) as follow:

$$
\frac{1}{\sqrt{1+\left(h^{\prime}(x)\right)^{2}}} \frac{\partial}{\partial x}\left(k(x) \frac{1}{\sqrt{1+\left(h^{\prime}(x)\right)^{2}}} \frac{\partial u}{\partial x}\right)+\frac{g h^{\prime}(x)}{\sqrt{1+\left(h^{\prime}(x)\right)^{2}}}=0,
$$

which is equal to

$$
\frac{\partial}{\partial x}\left(k(x) \frac{1}{\sqrt{1+\left(h^{\prime}(x)\right)^{2}}} \frac{\partial u}{\partial x}\right)+g h^{\prime}(x)=0 .
$$

By giving a higher priority to $k / u$, and not to the surface water flux, we can make a variable re- 
placement, that is, $U=u / k, K=k^{2}$. Then eq. (2) can be changed into

$$
\frac{\partial}{\partial x}\left(K(x) \frac{1}{\sqrt{1+\left(h^{\prime}(x)\right)^{2}}} \frac{\partial U}{\partial x}\right)+g h^{\prime}(x)=0 \text {. }
$$

By integrating both sides, eq. (3) can be changed into

$$
\int K(x) \frac{1}{\sqrt{1+\left(h^{\prime}(x)\right)^{2}}} \frac{\partial U}{\partial x} \mathrm{~d} x+\int g h^{\prime}(x) \mathrm{d} x=0 .
$$

Because of $\left.\frac{\partial u}{\partial x}\right|_{x=0}=\left.\frac{\partial u}{\partial s}\right|_{s=0}=0$, so $\left.\frac{\partial U}{\partial x}\right|_{x=0}=\left.\frac{\partial U}{\partial s}\right|_{s=0}=0$. We could get the following equation:

$$
K(x) \frac{\partial U}{\partial x}+g h(x) \sqrt{1+\left(h^{\prime}(x)\right)^{2}}=0 .
$$

As mentioned above, $K(x)$ is a constant within a finite area. $K(x)=\left\{\begin{array}{ll}K_{1} & 0<x<X_{1}, \\ K_{2} & X_{1}<x<X_{2} \\ K_{3} & X_{2}<x<X_{3},\end{array}\right.$, where $K_{1}, K_{2}$ and $K_{3}$ are constants. $X_{1}$ and $X_{2}$ indicate respectively the level coordinate of transform points between two land use types. $X_{3}$ is the maximum value of the level coordinate of the hill slope.

\section{Estimation of coefficients of model}

With soil moisture data obtained from field measurements in the different land use types on loess hill slopes, we could derive values of $K_{1}, K_{2}$ and $K_{3}$. Before calculation, we can make the following analysis:

when $0<x \leqslant X_{1}, K(x)=K_{1}$, by integrating eq. (4) from 0 to $x$, we can get

$$
K_{1} U(x)-K_{1} U(0)+\int_{0}^{x} g h(\xi) \sqrt{1+\left(h^{\prime}(\xi)\right)^{2}} \mathrm{~d} \xi=0 ;
$$

when $X_{1}<x \leqslant X_{2}, K(x)=K_{2}$, by integrating eq. (4) from $X_{1}$ to $x$, we can get

$$
K_{2} U(x)-K_{2} U\left(X_{1}\right)+\int_{X_{1}}^{x} g h(\xi) \sqrt{1+\left(h^{\prime}(\xi)\right)^{2}} \mathrm{~d} \xi=0 ;
$$

when $X_{2}<x \leqslant X_{3}=X, K(x)=K_{3}$, by integrating eq. (4) from $X_{2}$ to $x$, we can get

$$
K_{3} U(x)-K_{3} U\left(X_{2}\right)+\int_{X_{2}}^{x} g h(\xi) \sqrt{1+\left(h^{\prime}(\xi)\right)^{2}} \mathrm{~d} \xi=0 .
$$

Within $0<x \leqslant X_{1}$, that is, on grassland, there are three measurement points. We can derive three equations:

$$
K_{1} U\left(x_{1}\right)-K_{1} U(0)+\int_{0}^{x_{1}} g h(\xi)+\sqrt{1+\left(h^{\prime}(\xi)\right)^{2}} \mathrm{~d} \xi=0,
$$




$$
\begin{aligned}
& K_{1} U\left(x_{2}\right)-K_{1} U(0)+\int_{0}^{x_{2}} g h(\xi)+\sqrt{1+\left(h^{\prime}(\xi)\right)^{2}} \mathrm{~d} \xi=0, \\
& K_{1} U\left(x_{3}\right)-K_{1} U(0)+\int_{0}^{x_{3}} g h(\xi)+\sqrt{1+\left(h^{\prime}(\xi)\right)^{2}} \mathrm{~d} \xi=0 .
\end{aligned}
$$

From eqs. (8), (9) and (10), we can derive equations as below:

$$
\begin{aligned}
& K_{1}\left[U\left(x_{2}\right)-U\left(x_{1}\right)\right]+\int_{x_{1}}^{x_{2}} g h(\xi) \sqrt{1+\left(h^{\prime}(\xi)\right)^{2}} \mathrm{~d} \xi=0, \\
& K_{1}\left[U\left(x_{3}\right)-U\left(x_{2}\right)\right]+\int_{x_{2}}^{x_{3}} g h(\xi) \sqrt{1+\left(h^{\prime}(\xi)\right)^{2}} \mathrm{~d} \xi=0 .
\end{aligned}
$$

As mentioned above, $U=u / k$ is the inverse of real soil moisture. So, $U\left(x_{1}\right), U\left(x_{2}\right)$ and $U\left(x_{3}\right)$ are known. In addition, $h(x)$ is also a known function. Therefore, only $K_{1}$ is an unknown coefficient in eqs. (11) and (12). Since the number of equations is not equal to the number of unknown coefficient, we can derive $K_{1}$ using the least square method. $K_{2}$ and $K_{3}$ can be derived by the same method. In this way, we can obtain the value of $K(x)$.

\section{Solution to original model}

We used finite unit method to solve the original model. The major meaning of finite unit method is to find some function that is not equal to 0 as basic functions, and to take target functions as a linear combination of basic functions. For some specific questions and areas, the basic function can be chosen beforehand. Consequently, the key is to find coefficients of basic functions to target functions.

Firstly, we can divide level coordinates into 60 units and 5 units between two adjacent sampling points. Then we can construct the basic function $\varphi_{i}$, which, as a function, is equal to 0 except at two units within 60 units, and is a linear function within the two units. Within the part of $\left[x_{i-1}, x_{i}\right], \varphi_{i}$ is a line. It is equal to 0 at $x_{i-1}$ and 1 at $x_{i}$. Similarly, within part of $\left[x_{i}, x_{i+1}\right]$, $\varphi_{i}$ is a line, and is equal to 0 at $x_{i+1}$, and 1 at $x_{i}$.

According to the above statement, we can derive $U(x)$. Assuming that $u(x)$ posseses the form, $U(x)=\sum_{j=0} U_{j} \varphi_{j}(x)$. Thinking about the characteristics of eq. (3), multiplying both sides of it by an experimental function $V(x)$ that is not equal to 0 within a finite distance, and integrating within part of $[0, X]$, we can get

$$
\int_{0}^{X} V(x) \frac{\mathrm{d}}{\mathrm{d} x}\left(\frac{K(x)}{\sqrt{1+\left(h^{\prime}(x)\right)^{2}}} \frac{\mathrm{d} U}{\mathrm{~d} x}\right) \mathrm{d} x+\int_{0}^{X} g h^{\prime}(x) V(x) \mathrm{d} x=0,
$$

where the first integration can be taken as the sum of three integrations among three parts, $\left[0, X_{1}\right]$, $\left[X_{1}, X_{2}\right]$ and $\left[X_{2}, X\right]$. The form is $\int_{0}^{X}=\int_{0}^{X_{1}}+\int_{X_{1}}^{X_{2}}+\int_{X_{2}}^{X}$. 
Applying subdivision integration to the three integrations, we can get

$$
\begin{aligned}
& \int_{0}^{X_{1}} V(x) \frac{\mathrm{d}}{\mathrm{d} x}\left(\frac{K(x)}{\sqrt{1+\left(h^{\prime}(x)\right)^{2}}} \frac{\mathrm{d} U}{\mathrm{~d} x}\right) \mathrm{d} x=\left.V(x) \frac{K_{1}}{\sqrt{1+\left(h^{\prime}(x)\right)^{2}}} U^{\prime}(x)\right|_{0} ^{X_{1}}-\int_{0}^{X_{1}} \frac{K_{1}}{\sqrt{1+\left(h^{\prime}(x)\right)^{2}}} U^{\prime}(x) V^{\prime}(x) \mathrm{d} x, \\
& \int_{X_{1}}^{X_{2}} V(x) \frac{\mathrm{d}}{\mathrm{d} x}\left(\frac{K(x)}{\sqrt{1+\left(h^{\prime}(x)\right)^{2}}} \frac{\mathrm{d} U}{\mathrm{~d} x}\right) \mathrm{d} x=\left.V(x) \frac{K_{2}}{\sqrt{1+\left(h^{\prime}(x)\right)^{2}}} U^{\prime}(x)\right|_{X_{1}} ^{X_{2}}-\int_{X_{1}}^{X_{2}} \frac{K_{2}}{\sqrt{1+\left(h^{\prime}(x)\right)^{2}}} U^{\prime}(x) V^{\prime}(x) \mathrm{d} x, \\
& \int_{X_{2}}^{X} V(x) \mathrm{d}\left(\frac{K(x)}{\sqrt{1+\left(h^{\prime}(x)\right)^{2}}} \frac{\mathrm{d} U}{\mathrm{~d} x}\right) \mathrm{d} x=\left.V(x) \frac{K_{3}}{\sqrt{1+\left(h^{\prime}(x)\right)^{2}}} U^{\prime}(x)\right|_{X_{2}} ^{X}-\int_{X_{2}}^{X} \frac{K_{3}}{\sqrt{1+\left(h^{\prime}(x)\right)^{2}}} U^{\prime}(x) V^{\prime}(x) \mathrm{d} x .
\end{aligned}
$$

If the connective condition of an interface is

$$
\frac{k_{2}}{\sqrt{1+\left(h^{\prime}\left(X_{1}\right)\right)^{2}}} u^{\prime}\left(X_{1}+0\right)=\frac{k_{1}}{\sqrt{1+\left(h^{\prime}\left(X_{1}\right)\right)^{2}}} u^{\prime}\left(X_{1}-0\right)
$$

$\frac{k_{3}}{\sqrt{1+\left(h^{\prime}\left(X_{2}\right)\right)^{2}}} u^{\prime}\left(X_{2}+0\right)=\frac{k_{2}}{\sqrt{1+\left(h^{\prime}\left(X_{2}\right)\right)^{2}}} u^{\prime}\left(X_{2}-0\right)$ and $u^{\prime}(0)=u^{\prime}(X)=0$, then for $K$ and $U$, they become $\frac{K_{2}}{\sqrt{1+\left(h^{\prime}\left(X_{1}\right)\right)^{2}}} U^{\prime}\left(X_{1}+0\right)=\frac{K_{1}}{\sqrt{1+\left(h^{\prime}\left(X_{1}\right)\right)^{2}}} U^{\prime}\left(X_{1}-0\right)$,

$\frac{K_{3}}{\sqrt{1+\left(h^{\prime}\left(X_{2}\right)\right)^{2}}} U^{\prime}\left(X_{2}+0\right)=\frac{K_{2}}{\sqrt{1+\left(h^{\prime}\left(X_{2}\right)\right)^{2}}} U^{\prime}\left(X_{2}-0\right)$ and $u^{\prime}(0)=u^{\prime}(X)=0$, so, we have

$$
-\int_{0}^{X} \frac{K(x)}{\sqrt{1+\left(h^{\prime}(x)\right)^{2}}} U^{\prime}(x) V^{\prime}(x) \mathrm{d} x+\int_{0}^{X} g h^{\prime}(x) V(x) \mathrm{d} x=0 \quad \forall V(x) \in C_{0}^{\infty}[0, X] .
$$

According to the assumption $U(x)=\sum_{j=0} U_{j} \varphi_{j}(x), U^{\prime}(x)=\sum_{j=0} U_{j} \varphi_{j}^{\prime}(x)$. Because $V(x)$ is at random, we can take $V(x)=\varphi_{i}(x)$ directly, so,

$$
-\sum_{j=0}^{n} U_{j} \int_{0}^{X} \frac{K(x)}{\sqrt{1+\left(h^{\prime}(x)\right)^{2}}} \varphi_{j}^{\prime}(x) \varphi_{i}^{\prime}(x) \mathrm{d} x+\int_{0}^{X} g h^{\prime}(x) \varphi_{i}(x) \mathrm{d} x=0 .
$$

In fact, the above is a linear equation assembly for $U_{j}$. The coefficient matrix can be derived from the integration of known functions and function values. Certainly, the right-hand side of equation can be thought of as known. After solving the linear equation assembly, $U_{j}$ is $U(x)$ at every point $x_{j}$. Connecting these points with lines, we have the final $U(x)$ by the definite units method. Then, using the inverse of $U(x)$, we can derive the distribution of soil moisture along a hill slope. The distributions of soil moisture on grassland-slope farmland-woodland slope, on 
slope farmland-grassland-woodland slope and on slope farmland-woodland-grassland slope are shown in figs. $2-4$ respectively.

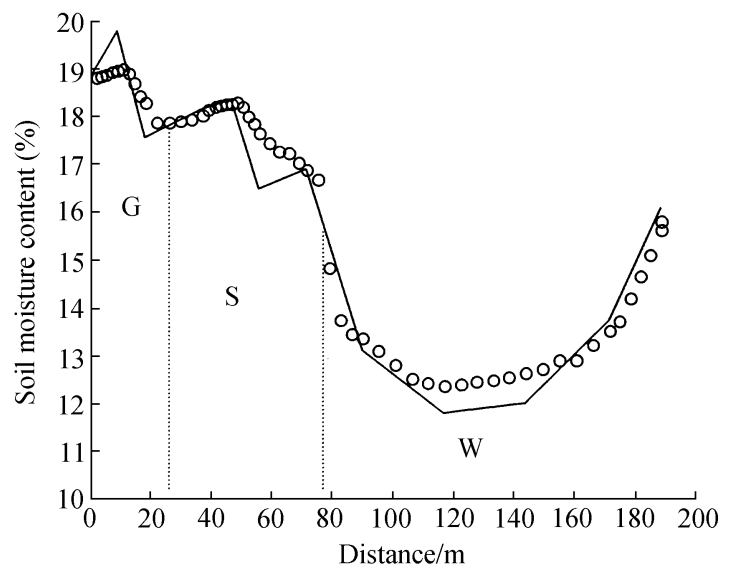

Fig. 2. The distribution of soil moisture on the grassland-slope farmland-woodland slope. G, grassland; S, slope farmland; W, woodland. The real line connects measurement data; circles are the computed values.

\section{Discussion}

The field measurement of soil moisture is a hard work. The mathematical model can simulate the distribution of soil moisture on hill slope during the course of rainfall infiltration using limited measured data. Figs. 2-4 show that the results obtained from calculation are smoother than those obtained from measurement . The reason is that the measured data is limited, the curves derived from them are not smooth. In addition, the values computed from the interface of two different land use types evidently jump, representing the effects of different land use on the soil moisture. The results are significant and cannot be shown by measured data. Furthermore, the model mainly considered the amount of water infiltrated into the soil from rainfall but the influence of soil character on rainfall infiltration was not considered. Therefore, it is only applicable to slopes whose soil characteristics are relatively uniform.

It is clear from the simulated and measured results that lower part of the slope has the highest soil moisture content, upper part of the slope has a relatively low soil moisture content, and middle part of the slope has the lowest soil moisture content at the slope transects. The middle part 
and lower part of the slope have the highest and lowest slope gradient respectively according to the slope gradient measurements. From this, the spatial distribution of soil moisture content is mainly affected by slope gradient and landscape position. The land use structures can also have some effects on the spatial distribution of soil moisture content. The mean water contents of $0-70$ $\mathrm{cm}$ soil is the highest for land use structure type of slope farmland-woodland-grassland, relatively low for grassland-slope farmland-woodland, and the lowest for slope farmland-grassland- woodland. Therefore, it is crucial that land resources are used reasonably according to the slope gradient and the position on the conservation of soil moisture.

Acknowledgements This work was jointly supported by the National Natural Science Foundation of China (Grant No. 49725101) and the Chinese Academy of Sciences (Grant No. KZCX2-405). The authors thank Mr. Michael F. Dadd from U.K. for improving the English of the manuscript.

\section{References}

1. Grayson, R. B., Western, A. W., Towards areal estimation of soil moisture content from point measurements: Time and space stability of mean response, Journal of Hydrology, 1998, 207: 68-82.

2. Fu Bojie, Wang Jun, Ma Keming, Effect of land use on soil moisture in loess hill area, Bulletin of National Natural Sceience Foundation of China (in Chinese), 1999, (4): 225-227.

3. Fu Bojie, Chen Liding, Ma Keming, The effect of land use change on the regional environment in the Yangjuangou catchment in the loess plateau of China, Acta Geographica Sinica (in Chinese), 1999, 54(3): 241—246.

4. Fu Bojie, Chen Liding, Ma Keming et al., The relationships between land use and soil conditions in the hilly area of the loess plateau in northern Shaanxi, China, Catena, 2000, 39: 69-78.

5. Fu Bojie , Chen Liding, Agricultural landscape spatial pattern analysis in the semi-arid hill area of loess plateau, China, Journal of Arid Environments, 2000, 44(3): 291-303.

6. Yang Wenzhi, Shao Mingan, Peng Xinde et al., The relationships between environmental aridity and soil moisture in the loess plateau, Science in China, Ser. D (in Chinese), 1998, 28(4): 357-365.

7. Gomez-Plaza, A., Alvarez-Rogel, J., Albaladejo, J. et al., Spatial patterns and temporal stability of soil moisture across a range of scales in a semi-arid environment, Hydrological Processes, 2000, 14: 1261—1277.

8. Shao Mingan, Horton, R., Exact solution for horizontal water redistribution by general similarity, Soil Science Society of America Journal, 2000, 64(2): 561-564.

9. Shao Mingan, Yang Wenzhi, Li Yushan, A model of soil moisture extraction by plant roots, Acta Pedologica Sinica (in Chinese), 1987, 24(4): 295-305.

10. Wang Xiuying, Cao Wenhong, Summarization about mechanism and mathematics simulation of soil erosion and sediment yield on slope surface, Journal of Soil Erosion and Soil and Water Conservation (in Chinese), 1999, 5(3): 87-92.

11. Bai Qingjun, Liu Yaxiang, Integrated model of runoff generation over valley slope surface, Journal of Soil Erosion and Soil and Water Conservation (in Chinese), 1999, 5(3): 54-58.

12. Anderson, M. G., Kneale, P. E., Topography and hillslope soil moisture relationships in a catchment of low relief, Journal of Hydrology, 1980, 47: 115-128.

13. Western, A. W., Blöschl, G., Grayson, R. B., Geostatistical characterisation of soil moisture patterns in the Tarrawarra catchmetn, Journal of Hydrology, 1998, 205: 20-37.

14. Western, A. W., Grayson, R. B., The Tarrawarra data set: soil moisture patterns, soil characteristics, and hydrological flux measurements, Water Resources Research, 1998, 34(10): 2765-2768.

15. Li Yong, Yang Juncheng, Zhu Yongyi, Using ${ }^{137} \mathrm{Cs}$ and ${ }^{210} \mathrm{~Pb}$ assess the sediment in a dam reservior catchment on the Loess Plateau, China, in China Nuclear Science and Technology Report, Beijing: Atomic Energy Press, 1997, 1—15.

16. Fitzjohn, C., Ternan, J. L., Williams, A. G., Soil moisture variability in a semi-arid gully catchment: implications for runoff and erosion control, Catena, 1998, 32: 55—70. 